\title{
Research
}

\section{Forestry and Road Development: Direct and Indirect Impacts from an Aboriginal Perspective.}

\author{
Marie-Christine Adam ${ }^{1}$, Daniel Kneeshaw ${ }^{1}$ and Tom M. Beckley ${ }^{2}$
}

\begin{abstract}
The forest industry is a significant contributor to the development of roads and most are constructed on Aboriginal territories. Many Aboriginal communities are isolated both socially and economically and Aboriginal cultures are often described as having inherent socio-environmental relationships. Aboriginal communities, therefore, may be the most likely to benefit and be most vulnerable to the impacts of road development. We use a case study approach to explore how an Aboriginal community interprets and responds to the increasing development of roads in its territory. The results are interpreted using the theory of access in order to frame the interactions between people and nature within a cohesive system which includes elements which are spatially located, flow, interact, and can be disturbed. The dominant themes discussed as being affected by the influence of roads on access included issues of the following nature: Aboriginal, hunting, foreign, territorial and environmental. Issues pertaining to Aboriginal actors as opposed to foreign actors such as the industry or non-aboriginal hunters and fishers dominated discussions. Although the positive effects provided by roads were alluded to, focus tended towards the affected relationships and ties between the territory, the environment and Aboriginal members. Roads are associated with changes in traditional roles and practices which benefit individualistic behaviors. The access mechanisms mediating and controlling the use of resources through traditional norms and roles such as sharing, asking permission, and helping in the practice of traditional activities no longer apply effectively. Changes in the traditional spatial organization of the territory have minimized the influence of knowledge, identity, and negotiation in mediating access among communities. Results highlight that conflicts have thus resulted between and among Aboriginal communities. Also, perception of the role of the environment and ways in which traditional practices occur has altered important socio-environmental dynamics which are part of Aboriginal culture.
\end{abstract}

Key Words: forest roads; Aboriginal access theory; traditional occupation; socio-environmental; integration.

\section{INTRODUCTION}

The forest industry is a significant contributor to development and maintenance of road networks. However, roads pose a challenging forest management problem. First of all, the forest industry constructs a large number and expanse of roads in forested areas. In Canada, there are $68,437 \mathrm{~km}$ of permanent primary roads and $15,401 \mathrm{~km}$ are permanent forest roads (Bourgeois et al. 2005). If secondary and tertiary forest roads were included the number would increase. For example, in BC alone the total number of forest roads is estimated to be between 400,000 and 550,000 km (Daigle 2010). Second, most road development by forest companies occurs in territories often occupied by Aboriginal peoples. In Canada for example, $80 \%$ of First Nation communities are located in the productive regions of boreal and temperate forests and are thus very close to forestry activities (Smith 2004).

Roads are traditionally associated in the literature with a limited set of environmental and social benefits and impacts. On one hand, roads are associated with economic growth and national wealth (Wilkie et al. 2000). In Nelson et al. (2006) roads are viewed as a solution to the "poverty trap". Better rural transportation is a principal factor for improving livelihoods especially in developing countries through better access to markets, increased social mobility, migration, and greater economic opportunities. The development of roads is

${ }^{1} \mathrm{UQAM}-\mathrm{CEF},{ }^{2} \mathrm{UNB}$ faculty of forestry and environmental management also viewed as a means to expand into a territory, tap into otherwise inaccessible resources, and provide new opportunities.

On the other hand, there is a growing body of literature highlighting the negative aspects associated with development of roads. Roads are associated with ecological disturbances and landscape degradation. In conservation biology for example, many researchers agree that road density is a good indicator of intensive use and the human footprint on the landscape. Some, like Crist et al. (2005) therefore advocate a high value for roadless areas as an integral part of conservation strategies. Reviews by ecologists such as Trombulak and Frissel (2000) and Formann (2000) outline the ecological effects of roads: 1) habitat destruction, 2) species mortality due to collision, 3) altered animal behaviors, 4) changes to physical and chemical environments, 5) introduction of exotic species, and 6) increased anthropogenic use of the territory. Increased poaching, illegal logging, and squatting have also been identified as a result of road development.

Aboriginal communities could benefit from aspects of road development since many in Canada are isolated both socially and economically. Benefits could include increased mobility to access forest resources and economic and employment opportunities associated with the forestry industry. Most aboriginal communities in Canada are located in the forest 
regions which are generally the more northern and isolated areas of Canada (NRCan 2009). In Quebec, the unemployment rate, education, and average earnings of Aboriginal people are significantly lower (a gap of approximately $20 \%$ ) than that of non-Aboriginal people (Ballardin and O'Donnell 2006). For these reasons, they may be the most likely to benefit and be most vulnerable to the impacts of road development. Vulnerability may be due to changes in land use brought about by road networks. Several land use and occupancy studies testify that indigenous people had high use of the land before the presence of roads (Tobias 2010). Aboriginal cultures are also described with inherent socio-environmental relationships (Davidson-Hunt and Berkes 2003, Stevenson 2006, Berkes 2008). Maintaining these relationships is a concern for Aboriginal communities facing rapid and significant environmental changes caused by forestry activities.

In Canada for example, the 1970s were characterized by large scale forestry operations. These resource development efforts were accompanied by significant road development. Forestry operations occurring on Aboriginal lands caused significant changes in the age and structural compositions of forests and developed many roads to extract timber. In some communities such as Kitcisakik (Québec), more than $60 \%$ of their territory has been logged since the beginning of large scale industrial forestry 40 yrs ago (Papatie 2004). In the Nitassinan (Innu Nation forest) of District 19 in Labrador, a 50\% reduction in the landbase available for forestry operations was negotiated to incorporate Innu values and concerns (Forsyth et al. 2003). The nature and the rate of environmental changes have had an impact on Aboriginal socio-environmental dynamics at rates which are difficult for these communities to integrate (Merkel 2007). Road development is occurring in Aboriginal community contexts complicated by a series of pressures whose impacts are difficult to isolate as they interplay with one another.

Elements other than traditional benefits and costs of roads previously mentioned should be considered. For example, although initially roads facilitate and physically increase the ability to use resources, other changes may occur with increasing road densities (Trombulak and Frissel 2000, Bourgeois et al. 2005). The perception of the benefits from roads in the short versus long term is at least in part a function of how much road development is occurring (Kneeshaw et al. 2010). Are the initial benefits provided by roads maintained with increasing road networks and road densities? As roads enable resources to be used, they also provide opportunities for resource development efforts as well as changes in community access dynamics. Roads increase resource use by non-Aboriginal hunters, recreationists, and for nonAboriginal resource development. According to Sikor and Lund (2009), access to resources is often contested and rife with conflict especially in societies where normative and legal claims to resources are competitive. Many Aboriginal communities are asserting their rights to land and resources and from their perspective, there is a climate of uncertainty when rights and claims to resources are considered.

There is a tendency to view roads and access in tandem. Access is usually defined as the ability to benefit from things. In management, the effects of roads are often limited to their impacts on a resource and as affecting access to the resource. It is a pattern oriented point of view in which the effects of roads on a landscape are organized along a biophysical and social gradient (Cumming 2011). In this sense, roads are assessed by the physical nature by which they provide access to a territory and the movement they permit within their networks. The interaction between roads and access is perceived as being limited and dictated through property rights and laws. In this point of view, the system is composed of the structural components of access: roads, rights, and laws.

According to Cumming (2011) interactions between people and nature should be framed within a cohesive system which includes elements which are not only spatially located (the structural components), but also flow, interact, and are disturbed (the relational components). This system has an identity and a level of resilience and thus the components and their relations need to be maintained in relation to a given perspective and problem (Cumming 2011). Indeed, access is a complex issue which involves the promotion of other social, cultural, and environmental values (Ribot and Peluso 2003). Property and access are a personal issue which falls beyond the realm of laws (Krueckeberg 1995). As mentioned in Ribot and Peluso's (2003) theory of access, access is actually the ability to benefit from things including material objects as well as persons, institutions, and symbols. According to the theory of access, there are many actors that seek to benefit from access. These actors interplay via social relations that are influenced by access mechanisms such as knowledge, technology, social identity, capital, labor, authority, and markets. The social relations between actors influence how access to resources is gained, controlled, and maintained. Social relations dictate access through a variety of means including interplaying norms, power, authority, property, and control over territorial occupational patterns and resource use. There are therefore complex and overlapping webs of relations and mechanisms which organize actors and their access to resources. Roads are only one of the many mechanisms involved in access. Roads are one of the technological mechanisms of access which will have multiple levels of impact because they are involved in a web of social relations that shapes benefit flows. The changes in access brought about by development of road networks need to be assessed through both structural and relational issues.

Community responses to roads are an important factor to consider in development efforts. According to Shindler et al. (2002), forestry professionals need to understand how natural 
systems function and are sustained as well as how people interpret and respond to changes in forest settings, policy decisions, and management institutions. Community responses to roads may also help identify relational and structural issues especially those related to resource development, access, socio-environmental dynamics, and territorial competition for claims to the land. Some of the relational changes associated with road development may be classified by Turner et al. (2008) as invisible losses: impacts which are not widely recognized in decisions about resource planning and decision making because they are an indirect or cumulative result of management decisions or policies. The invisible losses include: cultural/lifestyle losses, loss of identity, loss of self-determination and influence, emotional and psychological losses, loss of order in the world, knowledge losses, and indirect economic losses and lost opportunities (Turner et al. 2008).

We use a case study approach to explore how a Canadian Aboriginal community with an already high density of roads on its territory interpreted and responded to development of road networks created for forestry purposes. We use Ribot and Peluso's (2003) access theory to determine how important factors emerging from respondent interpretation of road development are associated with road influence in benefitting or losing from forest resource access: 1) Who is most affected by the influence of roads on access? 2) How are roads changing the way that the resource is being used? and 3) What access mechanisms are changing in association with road development? Although the theory of access approaches a highly comprehensive notion of access issues, we only looked at how the theory applies to roads. We are specifically interested in the theory's definition of access which goes beyond the structural components of access to incorporate social and environmental relations and thus the various community levels affected by road development. By looking at roads through the lens of access theory we hoped to develop an understanding of the socio-environmental and the social relations that they affect.

\section{STUDY AREA}

\section{Kitcisakik}

Kitcisakik is an Algonquin community (population 385) located in the Réserve faunique La Vérendrye in Quebec, Canada. The environment is a key component of Kitcisakik culture. According to Papatie (2004) the community members are the guardians of this territory and have the responsibility of ensuring its "harmonious" use to preserve its heritage for future generations. The territory $\left(5227 \mathrm{~km}^{2}\right)$ is composed of mixedwood forest at the limit of the yellow birch - balsam fir and white birch-balsam fir bioclimatic zones of the boreal forest. It is on this territory that the community members live, occupy, and practice traditional activities such as trapping, hunting, camping, and canoeing. A small portion of the community still practices semi-nomadic living arrangements between a summer and a winter settlement.

In general, Aboriginal territorial organization has gone through many changes since European contact. For example European colonialism and efforts towards sedentary patterns have had significant impacts. The Kitcisakik territory has traditionally been divided into family territories which organized resource use. Physically, there was little access between and within family territories and rights were held by trapline holders. What could be referred to today as trespassing was physically difficult making it beneficial for community members to hunt in their own family territory. Otherwise when resources were scarce, it was necessary to ask permission to hunt in another family's territory because access points and knowledge of the forest were limited to the family holding the trapping rights. Although physical access to resources within the territory may have been difficult there was a high need to use and occupy the land. Activities such as hunting, trapping, portaging, and camping are among those that were traditionally practiced on the land. A traditional regime of mutual dependency and community property norms was held in place by both the family territorial organization system and cultural principles which are described in Kitcisakik as the four community principles (sharing, honesty, mutual aid, and respect). To date, occupancy and territorial organization has been affected by a multitude of factors including, among others, road development, intensive resource extraction from industries, improved means of transportation, and increased access into the territory by other communities and nonAboriginals.

The Kitcisakik community has shown an increasing interest in the activities of the forest industry since 1998 (Papatie 2004). Today $43 \mathrm{~km}^{2}$ per year are logged on the territory (Papatie 2004) and more than $60 \%$ of the territory has been logged since the beginning of large scale industrial forestry 40 yrs ago. Harvesting was largely composed of extensive clear-cuts although some selective logging also occurred. Road development is not a novel issue for the community as roads have generally been developed in proportion to timber extraction efforts. There are now $4834 \mathrm{~km}$ of roads (all road types included) in Kitcisakik most constructed for forest timber extraction purposes.

The community is isolated from major centers and markets. The education level is low where $82.3 \%$ do not have high school, diploma, college certificate, nor university degree. It is poor with few employment opportunities $(35.3 \%$ employment rate) and lower revenues than the rest of Québec (54\% difference in the median income for people 15yrs and over; StatCan 2006). In the community there is neither permanent water, nor sewers, nor electricity. 


\section{Description of the population sampled}

This project is one among many projects originating from a partnership between the community of Kitcisakik and the University of Québec in Montreal. The partnership was initiated due to the community's growing interest in vocalizing their issues, values, and goals regarding the changes occurring in their forest environment. The ultimate goal of the partnership was therefore to better understand the community's relation to the forest and forestry activities as well as devising tools to better integrate their values and adapt forestry activities. All studies generated from this partnership were approved by the Ethics Review Boards of the University of Québec in Montreal. All participants signed an informed consent form, which was read to them. There was no remuneration for study participation.

The results presented here were obtained to accumulate information such that appropriate tools to integrate Aboriginal values into forestry activities could be devised. The individuals interviewed are believed to be those most aware and active in forest related issues in the community. The forestry committee was the community institution used to approach these individuals. The forestry committee is the Aboriginal institution which was specifically developed by Kitcisakik to ensure the community's participation in forest management, protect Aboriginal values and objectives, discuss measures in which management of some of the territory can be shared in the short term, and discuss measures towards self-governance and management (Papatie 2004). The members voluntarily choose to work with or for the committee and ranged in age from young (early 20s) to elders (when issues related to traditional activities need to be discussed). Because of the voluntary nature of membership in the forestry committee, members vary in numbers and people from year to year and season to season depending on competing community job opportunities and issues of concern in the community. There is only one permanent member of the forestry committee. Members receive training and work in forest related activities in the territory. These activities range from doing forest inventories for forestry companies and devising fuelwood exchange programs, to creating trails for educational purposes which expose aboriginally important flora. The forestry committee members can therefore easily and effectively participate in forest related issues.

\section{METHODS}

We used questionnaires with both open and closed ended questions to lead into semi-structured interviews which were completed by 10 members of the forestry committee in 5 interview sessions ( 2 individual interviews, 1 group of 2 and 2 groups of 3). Two women (W1 and W2: 38-50 yrs old; fewer women participate in forestry committees [Richardson et al. 2011]), 4 young men (Y1-4: 20-35 yrs old), and 4 men (M1-4: $38-50$ yrs old) participated in the interviews. One of the older members is considered an elder.
Interviews began by introducing the project and showing members a map of the road network in the territory. Interviews lasted between 1 and 2 hrs. To explore the physical, environmental, and social realms of forest committee responses to road development, the interviews were divided into three sections discussed in random order. One section pertained to the effects of roads on culture (Do roads affect the 4 principles of the Kitcisakik community: respect, mutual aid, honesty, and sharing?). The second section explored the effect of roads on the environment (forest, health, trees, fauna, etc.). The third section explored forest committee responses to the physical nature of road development: 1) road use (by hunters, aboriginals, community members, and industry);2) road type (primary, secondary, tertiary, paved, and size); 3) road condition (use by ATV, cars, maintenance); 4) road location (are roads in sacred areas, or important community areas); and 5) number of roads on the territory (too many or not enough roads). Questions began as true or false but were then discussed as open ended questions where comments were noted and discussion encouraged.

The results were interpreted using Ribot and Peluso's (2003) theory of access. As respondents reacted to roads in the context of their environmental, cultural, and physical nature they were in fact responding to some of the key elements of access theory such as: actors (those people, families, community, and institutions which will either benefit or lose from access created by roads); resources (access to which actors seek to benefit from with roads); and mechanisms (rights based, illicit, structural, and relational means used to include, reinforce, or gain access). According to the theory it is the actors, their values, and their social relations which form the access issues influenced by roads. Therefore interview responses were coded to identify dominant themes regarding the effects of road development as either benefiting or costing residents of Kitcisakik. We then categorized the themes according to the key elements of access theory (actors, part of the resource being accessed, or an access mechanism). Interview responses were also interpreted according to the relations between actors, resources, and for emerging access issues. Although the results are associated with roads, roads serve as an indicator and platform where community, environmental, and development issues can emerge. Roads may not be the unique direct causal factor but more likely, according to respondents, a proxy for their effects.

An informal validation exercise was also performed. We presented the results to the forestry committee to determine if there were gaps in our understanding of the interviews, and whether the committee was in concordance with our interpretations. We also interviewed an aboriginal member from the Maiyoo Keyoh, (interviewed 11/01/2010). The Maiyoo Keyoh (Keyoh is a family territory) of British Columbia, Canada, developed forestry scenarios to assist the members in participating in future development and 
establishment of management decisions in their forest $(17,013$ ha) which has undergone increasing forestry operations over the past 40 yrs. When defining scenario preferences, roads emerged as a determining parameter against many scenarios (Morben et al. 2009). Furthermore, the Maiyoo Keyoh are presently concerned with the resulting roads planned as a consequence of the increasing forestry activities in their territory (Morben et al. 2009). The level of disturbance as a result of forest operations is projected to increase from $17 \%$ to $84 \%$ of the territory. In this validation exercise we asked how roads affected the Maiyoo Keyoh territory. The purpose was to determine whether similar issues would be observed in a different community at a different geographic site. All comments and ideas extracted from the interview were used to check and corroborate the results from the Québec study (results are presented in the appendix). The results discussed hereafter summarize the Kitcisakik forestry committee interpretations of developing road networks on their territory validated by the community members themselves.

\section{RESULTS AND DISCUSSION}

\section{What are the access themes influenced by roads?}

Before applying the theory of access, the following dominant themes discussed in the interviews were identified as being affected by increasing road networks. These themes are not mutually exclusive and represent the Kitcisakik forestry committee perspective:

1. Aboriginal: These can be divided into intra-, interAboriginal community dynamics and general Aboriginal values (those which are not specific to the case study but which are Aboriginal issues in nature) effects.

2. Hunters in general (sports, poaching, and aboriginal hunters): Road development has facilitated hunting activities by rendering the territory more accessible. This is true for community members, other Aboriginal communities, as well as non-Aboriginal hunters.

3. Foreign: The forest industry and non-Aboriginal hunters were specifically identified as new groups with stakes in the development of roads on the territory. They are viewed as foreign by the forestry committee because they have not historically occupied or used their territory nor collaborated with the community for territorial use.

4. Territorial: Road development has affected local territorial dynamics by opening the region to use by everyone and changing the way it is viewed and perceived by users in general (Aboriginal and non-Aboriginal peoples).

5. Environment: The ecological impacts of roads were noted by the members interviewed including effects on: edges (forest composition, structure and health in edges), forest tree composition (more young trees, more deciduous trees), dust, lakes (water composition), fish, and fauna ("the animals look for shelter"). Changes in Aboriginal community relationship to the environment were also noted by respondents.

Based on Ribot and Peluso's (2003) access theory, the themes identified were categorized as follows: the environmental theme is defined as a resource; the aboriginal, hunters, and foreign themes are defined as the actors; and the territorial theme is an access mechanism.

\section{Actors, resources, and access mechanisms}

The respondents refer to the environment as the resource that is affected by roads. The environment as a resource (as providing material goods which can technically be controlled by property rights) is an access issue where actors feel they are both benefiting and losing from road development. In the interviews, the environment was referred to: 1) for trapping and hunting, 2) as habitat for fauna and flora, and 3) as a food source. However, we also see issues identified as socioenvironmental dynamics and described by access theory to involve mechanisms of knowledge, norms, and beliefs which cannot be limited or controlled by property. In the interviews access to the environment was referred to as: 1) part of their culture, 2) part of their home and their identity, 3) a source of knowledge either spiritually, traditionally, historically, or practically, and 4) an important resource for their way of life.

In the interviews issues pertaining to Aboriginal actors, as opposed to foreign actors such as the industry and hunting, dominated discussions around road development. This may come as a surprise because increased access can often lead to what may be perceived as the intrusion by new and foreign actors to a territory (e.g. the forest industry and hunting activities). On one hand, respondents highlighted the implicit role of the forest industry in developing road networks. They mention that roads allow the forest industry to use the territory "without permission" (all respondents) and "dishonestly" (respondents W1, M3, M4 and Y2), thus disrespecting community cultural principles. The structure of the interview allowed such comments to emerge throughout; however, they were few in number per respondent and rarely expanded upon.

Hunting, on the other hand, was presented by respondents as two different categories of actors. In the first category, hunters are characterized as foreign actors (i.e., the sports nonAboriginal hunter). Although this actor intrudes on community rights, they are in many ways tolerated as their presence is both spatially and temporally predictable in Kitcisakik. Community members are aware of the territory and time available to these hunters because hunting is controlled by seasons and granted through licenses. The second category is of more concern and describes illegitimate hunting activities by non-Aboriginals (poaching) and Aboriginals (those hunting to sell or that don't follow cultural 
and community norms). In this category, importance was attributed to the fact that some hunting activities occur without consideration of local norms. According to the theory of access, these actors use illicit access mechanisms to benefit from resources. Although the issue of hunting needs to be clarified, this study shows that there was a direct and obvious connection made between foreign actors, access, and road development by the forestry committee. However, the main respondent concern was based on the access mechanism which differentiated between actors which is in this case illicit access mechanisms.

The territory is also a theme raised by respondents, which is an access mechanism according to Ribot and Peluso (2003). More specifically respondents refer to the importance of family territories, community territories, and the associated knowledge, ancestral rights and control rights, they feel they should exert. Respect and permission to use were the key issues which consistently emerged. These issues reflect changes occurring in Kitcisakik regarding the people's perception of territorial rights. These are important because according to Fernandez-Gimenez et al. (2008:147), "the erosion of respectself-respect, respect for elders, for community, for tradition, and for the land and animals- is the perceived cause underlying the failure of individuals to abide by customary norms." Although increased ability to use a territory may initially be viewed as a positive contribution, changes in the right to use the territory and the introduction of new open access mechanisms as described by Ostrom (1990) were shown to be problematic. Essentially open access occurs when access is available to all and when norms and the position of actors within social and socio-environmental relations are challenged thus preventing access mechanisms to function effectively. More specifically, the following changes in influences to territorial rights have occurred: cultural frames in resource access priority; access to technology as facilitating or preventing resource access; physical access to resources in determining who benefits; and access through authority and social identity in determining who benefits from the resources. Examples are discussed in the following sections.

\section{Global Aboriginal perception of benefits or losses due to roads}

In the interviews, positive effects provided by roads were not contested by respondents. Indeed, the benefits of roads remain at the surface of this entire study as respondents alluded to the increased ability to hunt, increased facility to perform traditional practices, and increased means to occupy the territory. Some specific examples of the physical access benefits roads could provide were mentioned such as: the facilitating effects of roads in providing communication and transportation of important resources and aid to elders (e.g., the fuelwood program); filling up freezers with more easily accessed game; decreased dependence on the environment; and decreased community dependency. Indeed these are benefits associated with roads as the structural components of access. However, respondents tended to focus on the affected relationships and ties between the previously mentioned factors rather than restricting discussions to the physical access benefits roads could provide. "Roads are useful but there is a limit" (respondent Y2). The theory of access stipulates that "access relations are always changing, depending on an individual's or group's position and power within various social relationships" (Ribot and Peluso 2003: 158). It is these changing relations that are a preoccupation as they affect important cultural norms and principles in Kitcisakik including: a) Aboriginal rights, knowledge, and identity, b) role and definition of the environment, c) community relations and experience with the environment, d) territorial organization, use, and rights, and e) respect and collaboration. In effect, respondents believe roads disturb relationships, values, and communication between factors rather than promote them. Indeed, as predicted, access is a personal issue.

\section{Relational issues between actors}

Ultimately, Aboriginal actors were presented as the dominant concern regarding access issues for the Kitcisakik forestry committee. Other studies have also shown that roads surface as an issue for communities (see appendix). For example, Peluso (1992) looked at the processes of social change as timber operations entered a west Kalimantan village with new roads, new physical access, and development of forest products. The author showed that although roads brought trucks, traders and collectors from elsewhere, increased villager access to outside markets and facilitated outsider's access to this remote area; enforcement of village claims and the capacity to maintain the traditional ethic of access were highlighted as complications. Indeed interview responses in this study also highlighted changes mostly associated with Aboriginal values, Aboriginal way of life, Aboriginal knowledge of the territory, Aboriginal perception of ancestral rights, and Aboriginal territorial organization. The changing Aboriginal relations which emerged in the interviews we conducted can be categorized as inter-Aboriginal, intraAboriginal and general Aboriginal values. These changes are discussed in further detail in the following paragraphs.

\section{Intra-Aboriginal relationships}

Rapid and accessible communication measures can have positive effects on a community such as reducing risk (pressures to hunt for subsistence are diminished) and are sought by community members through technological advances (vehicles and ATVs for transportation). In the interviews, however, changes in the ability to use and the right to use have affected Aboriginal values and Aboriginal way of life in Kitcisakik. Respondents now feel that roads are associated with changes in traditional roles and practices which benefit individualistic behaviors. For example, respondents mention that although available to all, changes in the rights to hunt and trap are problematic. Unlike the past, 
community members no longer ask permission to hunt, need help in the hunt, nor share the kill, "it has become easy to hunt ... now everybody can and fast" (respondent Y1). In effect, if everyone can do it alone and easily, the traditional norms and roles dictating who and with what rights they use resources no longer apply effectively. In Kitcisakik, these traditional roles were in fact access mechanisms mediating and controlling the use of resources through sharing, asking permission and helping in the practice of traditional activities. According to Agrawal (1995: 418) and Banuri and ApfellMarglin (1993: 10-18) such individualistic tendencies are a significant departure from the distinguishing characteristics of indigenous knowledge including among other characteristics: "not believing in individualist values" and "requiring a commitment to the local context unlike western knowledge which values mobility and weakens local roots."

The affected access mechanisms and the changes toward individualistic tendencies create conflict in Kitcisakik at many levels. The role of traditional "experts" (practitioners and protectors) in hunting has been minimized. The traditional collaboration needed in the past for hunting activities (sharing, asking permission, help in the kill, help returning the kill to the village) has been minimized. "Before, he had to think of the difficulties of others and the possibility of his own difficulties" (respondent W2). As well, conflict with the old norms dictating use rights exists between the younger users, the older generations and the territory leaders or protectors. "you can hunt from four wheels or cars" .... "the young don't even ask to go on the territory, they steal from our food storage (environment)" ..... "there is no more transmission" (respondents W2, M3, Y1 respectively). Miller et al. (2000) identified the importance of extending traditional teaching and values to younger generations as one of six recommendations for planning. Although respondents focus on the advantages of the "old ways" which may be perceived as a romanticized notion of the past and a fear for the contemporary lifestyles, the issue lies in the loss of Aboriginal access mechanisms mediating resource use. By interpreting the interviews with the theory of access, we note that there is a loss of formal and informal rights, local institutional organization, and intra community relations to manage the changes in Kitcisakik's territory. According to Dietz et al. (2003) these rules need to evolve to ensure successful commons governance. As a consequence, intra-community collaboration is minimized and intra-Aboriginal relationships are disturbed.

\section{Inter-Aboriginal relationships}

The same changes that affect intra-Aboriginal relationships are also affecting inter-Aboriginal relationships. Respondents expressed that not only are traditional roles and practices changing at the individual level but they are also occurring with the new spatial organization of family territories. According to respondents, roads dissect the territory, they cut through family territories, and they go through trails and hunting grounds. "It is a labyrinth of roads" (respondent M4). Not only do roads change the movement patterns and means of moving through a territory but they render family territories easily accessible to all and disturb the traditional spatial organization of the territory. Unlike non-Aboriginal mechanisms where land is marked with boundaries and driven by rights based mechanisms (property), the Aboriginal mechanisms which define a territory are driven by structural and relational mechanisms and defined by three criteria: knowledge, permission to use, and use/occupation. The family territory of this community plays an important role in access mechanisms because traditionally, it was the members who occupied, used and knew their respective territories that controlled and mediated access. To use another family's territory one had to ask permission as well as access family knowledge of that territory and its resources. These mechanisms have been affected in association with roads and changes have been especially problematic among Aboriginal communities. "People just occupy the land and don't ask permission. Sometimes the traps are stolen, sometimes we are surprised to see others (other communities) hunting in our territory..... there is no communication and no transmission" (respondent M1). Roads have affected the role of family territory as a source of knowledge, social identity, and in negotiating access.

Knowledge of the territory at the landscape scale has increased among the members of Kitcisakik and between the surrounding Aboriginal communities. It is no longer specialized nor divided among family territories. "There are no more hunting guardians" (respondent M2). Knowledge and availability of the land created by road developments is causing power shifts which are affecting the distribution of rights and control over the land and affecting community ties. "He forgets the other and affects the life of the other. The other's life is affected on top and has to find another spot to trap" (respondent W2). Knowledge of environmental cues determining the presence and potential of specific resources becomes superfluous and the little that is needed is easily available to the surrounding Aboriginal communities. The limits of knowledge as a mechanism influencing access have thus been extended to neighboring communities thus creating tension.

It has been suggested that social identity can mediate access (thus the need to ask permission) through membership in a group or community. Age, gender, ethnicity, religion, status, profession, place of birth, common education, or other attributes that constitute social identity (Ribot and Peluso 2003). In the interviews, the role of the family territory as a social identity which can mediate access to resources is minimized. There is no longer a perceived need to ask for permission (and enforcing rights) to enter a territory. Respondents highlighted an increasing tension which is especially problematic among neighboring Aboriginal 
communities where members of other communities are both using and hunting in Kitcisakik without permission. Roads are thus associated with heightened competitive claims for resources between communities.

Negotiation is a mechanism influencing how certain groups interact with others to allow a distribution of benefits (Ribot and Peluso 2003). Because of the previously mentioned change in the role of the family territory, negotiation mechanisms are also diminished. It is not just the road in itself which affects access mechanisms but the density of roads as well. There are so many roads that the role of the family territory as a social identity which can mediate, control, or negotiate access is difficult.

Fernadez-Gimenez et al. (2008) highlighted that the creation of clearer boundaries does not help emphasize the positive, cooperative attributes of social exchanges between communities. This is pertinent to roads because on one hand, roads create clear physical marks on the landscape which could be viewed as boundaries. On the other hand, the purpose of roads as facilitators of mobility and communication should emphasize these attributes and exchanges. However, roads seem to be viewed by respondents as artificial physical boundaries in conflict with traditional boundaries. In effect, the changes associated with road development have altered how privilege, reciprocity, and respect of one territory relative to another are assessed.

\section{General Aboriginal values}

From an Aboriginal perspective, it is an inherent Aboriginal right to practice and have access to traditional activities on the land and benefit from the resources. Although there are Aboriginal rights to use the land attributed by non -indigenous people, these rights are not meant to be used in the absence of traditional Aboriginal systems or laws. The changes in territorial perspectives, family territories and inter- intraAboriginal relations associated with roads are also changing the role of Aboriginal rights and relationships with tradition and culture. More specifically, the role of Aboriginal rights is changing from one which binds Aboriginal peoples, to one which allows individual members to perform specific activities: "people (aboriginal people in the community) will do things because of ancestral rights but do not try to ensure the sustainability of the resources" (respondent M1). Also the new ways to use and justify use of the land which are emerging in Kitcisakik require a redefinition of the Aboriginally defined rights which should dictate access to resources. Indeed, respondents mentioned that maintaining and respecting the relationship with the land is as important as maintaining Aboriginal rights to the land. "People (Aboriginal in the community) don't practice traditions" (M4). "They (community members) think they can do anything and have the right to do it but they forget their values" (M1).In this context it becomes important for Kitcisakik to manage the effects of road/resource development so that they can reasonably continue to exercise their tradition and culture within their territory under agreed understanding of Aboriginal rights.

\section{Relational issues with the resource: socio-environmental relations}

The results show that roads have changed environmental relations at many levels. More specifically perception of the role of the environment and ways in which traditional practices occur has altered important socio-environmental dynamics which are part of Kitcisakik's culture. For example, the environment was traditionally viewed among other things as food storage belonging to the community whose use was dictated by the cultural principles (sharing, respect, mutual aid, and honesty). However, the technological advances associated with roads and access (prominent use vehicles) and the increased ability to use resources (use of freezers) has changed this definition. According to respondents, people not only hunt for their subsistence but to also fill many freezers. "They no longer share the catch.... Now it is solitary, the whole moose goes into a freezer" (M1). "No one shares anymore, it is all easy ... many people even have 3 freezers" (M4). In effect the environment is becoming an easy pool of resources for the individual rather than the community and storage has been moved to the home rather than the environment.

The effects of roads on the landscape landmarks used and the methods employed to practice traditional activities have diminished the connection between the people and the environment of Kitcisakik. More specifically, access mechanisms which were traditionally based on portage routes and environmentally based landmarks (e.g., large white pine trees served to orient hunters towards productive lands) have changed to using roads as landmarks. The elder interviewed believes that there is a sense of laziness in the community now. "The people do not walk like they used to. The people no longer have legs, and no longer have arms" (W1). This laziness, although associated with people hunting from the road side also reflects that the people no longer take the time to know their territory. Respondents mention that the "space" in the woods has changed and "now people can no longer find themselves" in the environment (respondent W2, M4). Furthermore, the connection between people and fauna was noted (respondent W1): "They (animals) see everything and will no longer resist"; "the people no longer hear nor see songs."

The environmental experiences derived from traditional practices have also been affected by the rate and density of developing road networks in Kitcisakik. New environmental experiences are clashing with the old ways resulting in differing perceptions between generations regarding the role and importance of traditional and ancestral rights practiced in the environment. To the older generations, the increased 
accessibility and availability of environmental experiences has resulted in a decrease in the perceived value of traditional practices by younger generations. Although roads do not directly interfere with the pursuit of traditional practices, they have affected the means by which these practices occur. In concordance with Merkel (2007) skills are being lost as people are spending less time in the environment. Roads are thus not the only cause but they are an important contributing factor to the erosion of traditional relationships with the environment.

\section{CONCLUSION}

Roads benefit many Aboriginal communities by increasing community access to market centers and intra community communication. However, as with many aspects of development, roads provide some benefits but they come with costs in terms of traditionally important Aboriginal relations. The role of respect, collaboration, reciprocity, and identity in organizing the relations of one territory with another has been disturbed and implies important cultural changes in terms of beliefs and norms as well as spatial territorial organization. In Kitcisakik the ability to use resources has evolved disproportionately compared to the rights and norms dictating the use of resources. The repercussions associated with road development therefore need to be appropriately considered. Although it is clear that some benefits can be attained, the influence of roads needs to be thought of as having both structural and relational components.

The structural components are related to the physical influence of roads in a landscape and the associated benefits of movement through that landscape superficially influenced by property rights. Although increased mobility and access to resources were alluded to and therefore a benefit in themselves, it was the negative changes they had on relational components of access which dominated impressions.

The relational issues raised were not necessarily limited to roads as their direct causal factor. For example the changes that are raised here in terms of Aboriginal identity involve more than the effects of roads. Aboriginal identity is by no means defined by roads. Indeed the issues highlighted can be characterized as invisible losses (Turner et al. 2008) which can occur in many Aboriginal communities facing development pressures.

Based on this case study, road development needs to be managed to ensure the persistence of Aboriginal culture and their rights. Responses to road development have also served as a good indicator of important cultural and Aboriginal relational issues. Indeed, it is by appropriately considering all aspects of access as described by Ribot and Peluso's (2003) theory of access that we can begin to account for the tradeoffs between access to resources and the changing dynamics it imposes.

Using access theory was an effective tool to understand the important relations and personal Aboriginal dynamics which need to be considered in access issues. Changes in inter- and intra- Aboriginal community issues, cultural implications, the use and role of Aboriginal rights, and the role of important Aboriginal territorial organization issues were raised as a result of roads.

As is expected from exploratory research, a series of questions have emerged from this case study. We identified the need for further research which uses access theory where resource development efforts need to be integrated with many resource users. Comparing responses in many Aboriginal communities is also necessary to identify trends. Furthermore, identifying responses as a function of varying road densities, and responses to new roads versus old roads would also help differentiate between short-term and long-term impacts of road development. We hope that the ideas emerging from this study will facilitate and identify research needs such that the positive contributions versus losses due to road development can be appropriately weighed and accounted for.

Responses to this article can be read online at: http://www.ecologyandsociety.org/issues/responses. php/4976

\section{Acknowledgments:}

We would like to thank the community of Kitcisakik for their time, knowledge, dedication and patience. There is an infinite source of knowledge and spirituality which has helped us grow as individuals, researchers and scientists. We would also like to thank J. Munroe for his support and valuable knowledge which has helped better this article as well. We would also like to thank all reviewers and students which have been involved with this research.

\section{LITERATURE CITED}

Agrawal, A. 1995. Dismantling the divide between indigenous and scientific knowledge. Development and Change 26: 413-439.

Ballardin, A. and V. O'Donnell. 2006. Enquête auprès des peuples autochtones de 2001 : rapports provinciaux et territoriaux - Population autochtone hors rèserve. Produit no 89-618-XIF au catalogue de Statistique Canada. Statistics Canada, Ottawa, Canada. [online] URL: http://www5.statcan. gc.ca/bsolc/olc-cel/olc-cel?catno=89-618-X\&lang=fra.

Banuri, T. and F. Apffel-Marglin. 1993. Who Will Save the Forests? Knowledge Power and Environmental Destruction. Zed Books, London, UK.

Berkes, F. 2008. Sacred Ecology. Second edition. Routledge, New York, USA. 
Bourgeois, L., D. Kneeshaw, and G. Boisseau. 2005. Les routes forestières au Québec: les impacts environnementaux, sociaux et économiques. Vertigo 6(2): 2-9.

Crist, M. R., B. O. Wilmer, and G. H. Aplet. 2005. Assessing the value of roadless areas in a conservation reserve strategy: Biodiversity and landscape connectivity in the Northern Rockies. Journal of Applied Ecology 42(1): 181-191. http:// dx.doi.org/10.1111/j.1365-2664.2005.00996.x

Cumming, G. S. 2011. Spatial resilience: integrating landscape ecology, resilience, and sustainability. Landscape Ecology 26: 899-909. http://dx.doi.org/10.1007/s10980-011-9623-1

Davidson-Hunt, I. and F. Berkes. 2003. Learning as you journey: Anishinaabe perception of social-ecological environments and adaptive learning. Conservation Ecology 8 (1): 5. [online] URL: http://www.consecol.org/vol8/iss1/art5/

Daigle, P. 2010. A summary of the environmental impacts of roads, management responses, and research gaps: A literature review. British Columbia Journal of Ecosystems and Management 10(3):65-89.

Dietz, T., E. Ostrom, and P. C. Stern. 2003. The struggle to govern the Commons. Science (302): 1907-1912. http://dx. doi.org/10.1126/science.1091015

Fernandez-Gimenez, M. E., J. U. Hays, H. P. Huntington, R. Andrew, and W. Goodwin. 2008. Ambivalence toward formalizing customary resource management norms among Alaska native beluga whale hunters and Tohono O'odham livestock owners. Human Organization 67(2): 137-150.

Forman, R. T. T. 2000. Estimate of the area affected ecologically by the road system in the United States. Conservation Biology 14(1): 31-35. http://dx.doi.org/10.1046/ j.1523-1739.2000.99299.x

Forsyth, J., L. Innes, K. Deering, and L. Moores. 2003. Forest ecosystem strategy plan for forest management district 19 Labrador/Nitassinan 2003-2023. Innu Nation \& Department of Forest Resources \& Agrifoods (Government of Newfoundland and Labrador) Sheshatshiu, Labrador. [online] URL: http://www.env.gov.nl.ca/env/env assessment/projects/ y2003/1062/text.pdf

Kneeshaw, D. D., M. Larouche, H. Asselin, M.-C. Adam, M. Saint-Arnaud, and G. Reyes. 2010. Road Rash: Ecological and Social Impacts of Road Networks on First Nations. pp. 169-184 (Chapter 8), in M. G. Stevenson and D. C. Natcher, editors. Planning Co-existence: Aboriginal Considerations and Approaches in Land Use Planning. Edmonton: Occasional Publication No. 65, Canadian Circumpolar Institute (CCI) Press, University of Alberta (ISBN 978-1-896445-49-6).

Krueckeberg, D. A. 1995. The difficult character of property: To whom do things belong? Journal of the American planning association, Summer 61(3):301. http://dx.doi. org/10.1080/01944369508975644

Merkel, G. 2007. We are all connected: Globalization and community sustainability in the boreal forest, an aboriginal perspective. Forestry Chronicle 83(3): 362-366.

Miller, A. M., I. J. Davidson-Hunt, and P. Peters. 2010. Talking about fire: Pikangikum First Nation elders guiding fire management. Canadian Journal of Forestry Research 40 (12): 2290-2301 http://dx.doi.org/10.1139/X10-177

Morben, M., M. Kirk, N. Farrer, D. Dolejsi, and A. Sawden. 2009. Scenario Analysis for the Maiyoo Keyoh. Maiyoo Keyoh Society \& University of British Columbia. Maiyoo Keyoh society archives. FRST 424, April.

Natural Resource Canada (NRCan). 2009. Aboriginal Population and Forested Areas in: The atlas of Canada. Government of Canada http:index.html [accessed July 2011].

Nelson, A., A. de Sherbinin, and F. Pozzi. 2006. Towards development of a high quality public domain global roads database. Data Science Journal 5: 223-265. http://dx.doi. org/10.2481/dsj.5.223

Ostrom, E. 1990. Governing the commons: the evolution of the institutions for collective action. Cambridge University Press, Cambridge, UK. http://dx.doi.org/10.1017/ $\underline{\text { CBO9780511807763 }}$

Papatie, J. 2004. Vécu et réflexion de la communauté Anicinapek de Kitcisakik avec le régime forestier Québécois. Commission d'étude sur la gestion de la forêt publique Québécoise. Projets de réserves de biodiversité des lacs Vaudray et Joannes et du lac Sabourin. Abitibi/Baie James, Canada. 6212-01-203. [online] URL: http://www.bape.gouv. qc.ca/sections/mandats/vaudray-joannes/documents/DB17.pdf.

Peluso, N. L. 1992. The ironwood problem: (mis)management and development of an extractive rainforest product. Conservation Biology 6(2): 210-219. http://dx.doi.org/10.1046/ j.1523-1739.1992.620210.x

Ribot, J. C. and N. L. Peluso. 2003. A theory of access. Rural sociology 68(2): 153-181. http://dx.doi.org/10.1111/j.1549-0831.2003. tb00133.x

Richardson, K., A. J. Sinclair, M. J. Reed, and J. R. Parkins. 2011. Constraints to participation in Canadian forestry advisory committees: a gendered perspective. Canadian Journal of Forest Research 41:(3) 524-532. http://dx.doi. org/10.1139/X10-220

Shindler, B. A., M. Brunson, and G. H. Stankey. 2002. Social acceptability of forest conditions and management practices: a problem analysis. Gen. Tech. Rep. PNW-GTR-537. U.S. Department of Agriculture, Forest Service, Pacific Northwest Research Station. Portland, Oregon, USA. 
Sikor, T. and C. Lund. 2009. Access and property: a question of power and authority. Development and Change 40(1): 1-22. http://dx.doi.org/10.1111/j.1467-7660.2009.01503.x

Smith, P. 2004. Inclusion before streamlining: the status of data collection on Aboriginal issues for sustainable forest management in Canada. International Perspectives on Streamlining Local-level Information for Sustainable Forest Management. In; Innes, John L., Gordon M. Hickey and Bill Wilson (editors), International Perspectives on Streamlining Local-Level Information for Sustainable Forest Management, A selection of papers from a conference held in Vancouver, Canada, August 28 and 29, 2000. Information Report BCX-400. Pacific Forestry Centre, Canadian Forest Service, Natural Resources Canada, Victoria, BC.

Statistics Canada (StatCan). 2006. 2006 census release topics. Government of Canada. [online] URL: http://www12.statcan. ca/census-recensement/2006/rt-td/index-eng.cfm

Stevenson, M. G. 2006. The Possibility of Difference: Rethinking Co-management. Human Organization, Summer 65, no. 2 (Summer 2006): 176.

Tobias, T. N. 2010. Living Proof: The Essential DataCollection Guide for Indigenous Use-and-Occupancy Map Surveys. Union of BC Indian Chiefs and Ecotrust Canada. British Columbia, Canada.

Trombulak, S. C. and C. A. Frissell. 2000. Review of ecological effects of roads on terrestrial and aquatic communities. Conservation Biology 14: 18-30. http://dx.doi. org/10.1046/j.1523-1739.2000.99084.X

Turner, N. J., R. Gregory, C. Brooks, L. Failing, and T. Satterfield. 2008. From Invisibility to Transparency: Identifying the Implications. Ecology and Society 13(2): 7. [online] URL: http://www.ecologyandsociety.org/vol13/iss2/ $\underline{\operatorname{art} 71}$

Wilkie, D., E. Shaw, F. Rotberg, G. Morelli and P. Auzel. 2000. Roads, Development, and Conservation in the Congo Basin. Conservation Biology 14(6): 1614-1622. 


\section{Appendix 1- Validation Exercise}

We interviewed J. Munroe, a representative in charge of resource development issues for the Maiyoo Keyoh, (interviewed 11/01/2010) as a validation exercise. In this validation exercise we asked how roads affected the Maiyoo Keyoh territory in order to determine whether similar issues would be observed in a different community at a different geographic site. All comments and ideas extracted from the interview were then checked and validated against the Québec data. The Maiyoo Keyoh (Keyoh is a family territory) of British Columbia (Canada) developed forestry scenarios to assist the members in participating in future development and establishment of management decisions in their forest (17013 $\mathrm{Ha}$ ) which has undergone increasing forestry operations over the past 40 years. When defining scenario preferences, roads emerged as a determining parameter against many scenarios (Morben et al., 2009). Furthermore, the Maiyoo Keyoh are presently concerned with the resulting roads planned as a consequence of the increasing forestry activities in their territory (Morben et al., 2009). The level of disturbance as a result of forest operations is projected to increase from $17 \%$ to $84 \%$ of the territory.

The validation exercise raised similar preoccupations to those found in this study. The following paragraphs show how respect, value for the land, and socio-environmental dynamics have changed in association with road development.

The effects of roads on issues of respect and its effect on access mechanisms used to control and maintain access was raised. According to the respondent, traditional Keyoh land use and rules have changed. "The passing of respect for Keyoh has been lost". The way people travel the land is different. People travel down a road and have to go through other Keyoh to use their Keyoh, traditional routes are no longer used so the rules have changed. As such the families of other Keyohs often feel they are disrespected.

Road hunting was also raised as an issue affecting land use, traditional practices and socioenvironmental relations. "On one hand the older generations are disoriented by the new access mechanisms because they used to travel by trails and now they access by roads. On another hand the kids do not recognize the land in the same way as elders. People used to walk the trails now they use the roads. As a result their attachment to the land is challenged". The changes in knowledge (socioenvironmental or territorial) which influence access mechanisms were therefore mentioned here as well. The environmental experience derived from the environment has been changed and is also creating generational conflicts.

Intra-, inter-Aboriginal relations have been affected by roads as well as foreign relations in this case. "We (the keyoh and community) avoid access to the land. We don't go because we don't want to be seen nor do we want hunters to know where the cabin is. We feel alienated from the land. This fear exists because of hunters but also because of all other users including natives. We (community and keyoh members) build cabins which are hidden. The land is no longer ours and we don't feel we can protect it ... so we hide. This is taxing to the community. We (the community) have meetings to plan how to protect our culture. There is so much change and activity which we need to synthesize, it is exhausting and at the same time we are on guard to preserve our relationship with the land." In this 
case we get a sense of a loss of control over who and how actors can benefit from the resources. Roads are disturbing the role of Aboriginal identity and Aboriginal rights in influencing access.

Morben, M. and M. Kirk, N. Farrer, D. Dolejsi, A. Sawden. 2009. Scenario Analysis for the Maiyoo Keyoh. Maiyoo Keyoh Society \& University of British Columbia. FRST 424, April. 